$\begin{array}{ll}\text { DE } & \text { DE GRUYTER } \\ \text { OPEN } & \\ & \end{array}$

DOI: 10.2478/topling-2014-0008

\title{
The 'indisciplinarity' of stylistics
}

\author{
Sandrine Sorlin \\ Aix-Marseille University / LERMA / IUF, France
}

\begin{abstract}
This paper aims at showing why the stylistician can be construed as a prolific "impostor" in a most positive sense: pledged to no specific linguistic prophet, she can opt for different theoretical linguistic tools (in the sphere of pragmatics, critical discourse analysis, cognitive grammar, etc.) depending on her object of study and what her research question is. The liberty claimed by the stylistician explains why stylistics is the "undisciplined" child of linguistics, shirking any clear definition of its boundaries. It will be argued that stylistics can only exist as a cross-disciplinary field given its conception of language as fundamentally contextualized. If it was a discipline determined by clear-cut pre-established boundaries, stylistics would be far more "disciplined" but would run the risk of serving only itself. The broad goal of this paper is thus to evince that the "indisciplinarity" of stylistics constitutes its very def ining essence. With this aim in mind, it will demonstrate what stylistics owes to other disciplines, what it shares with similar language-based disciplines and what it can offer to other fields or practices of knowledge.
\end{abstract}

\section{Keywords}

Porous disciplinary boundaries, positive imposture, pragmatic stylistics, critical stylistics, cognitive stylistics, literary stylistics, stylistic sociolinguistics.

\section{Introduction}

Nothing less than a neologism could best define the essence of stylistics: it is a discipline practising indisciplinarity, in the sense that stylistics has created a space of its own ${ }^{1}$ by borrowing both its objects and theoretical tools from many different fields in the social sciences. We could consider it a branch of linguistics as an easy way to

\footnotetext{
1 Stylistics is no longer fighting for space as Ronald Carter puts it: "[Stylistics people] have a sense, like never before, that they are here to stay and it is no big deal now to worry about what part of the linguistic, literary or pedagogic territory they occupy. Although this does not mean that clear orientations are not given, it is up to others to worry about where they stand in relation to stylistics" (Foreword by Carter in Watson and Zyngier [eds], 2007, p. viii). Stylistics is indeed an established discipline with international recognition through peer-reviewed journals and institutional affiliations and associations (like PALA for instance) whose members regularly organize scientific events all over Europe and beyond.
}

establish its territory within a better-defined discipline. But as it tends to incorporate tools and theories belonging to various branches of linguistics, stylistics is too multifaceted today to be seen as a mere complement to linguistics.

A discipline allows us to "think knowledge", says Michel Foucault, but it inevitably erects excluding boundaries that better delineate its frontiers ${ }^{2}$. Stylistics however can be said to practise indisciplinarity ${ }^{3}$ in its very refusal

2 "A l'intérieur de ses limites, chaque discipline reconnaît des propositions vraies et fausses, mais elle repousse, de l'autre côté de ses marges, toute une tératologie du savoir. [...] Bref, une proposition doit remplir de complexes et lourdes exigences pour pouvoir appartenir à l'ensemble d'une discipline" (Foucault, 1979, p. 35).

${ }^{3}$ This word was coined by Laurent Loty against what he perceives as the paralysing and coercive effects of disciplinary frontiers: "si ce mot me paraît utile, c'est qu'il peut aider à régler l'apprentissage de la soumission qui va souvent de pair avec le respect des disciplines" (Loty, 2005, p. 246). 
to build up impermeable disciplinary frontiers. Its deliberately porous borders are what allow both importation and exportation. First, we will consider what stylistics owes to other disciplines that have helped it define itself. Second, we will try to delimit its territory vis-à-vis other languagebased disciplines that it shares much with. Lastly, we will see how stylistics itself promotes indisciplinarity, as it does not only take from or share with other (sub)disciplines, but it also gives; other fields and practices like sociolinguistics or teaching having borrowed from its specific conception of language.

\section{An undisciplined discipline}

Stylistics exploits discursive space that could be seen as the prerogative of other disciplines like literature (for literary texts), political science (for political speeches), or media and communication (for journalistic or magazine texts). But it applies to it tools that it borrows from another discipline linguistics and its various branches (systemic functional linguistics, pragmatics, cognitive grammar, corpus linguistics, to name but a few), and social and cultural theories that are inspired by sociology, psychology or critical feminist theory for instance. In so doing, stylistics does not merely practise interdisciplinarity in the sense that it does not aim at simply breaking down disciplinary frontiers: it has established itself as a bridge between the disciplines its feeds on and in so doing has set up its own disciplinary space. Taking the example of the stylistic study of literary texts, the in-between disciplinary space of stylistics can be thus illustrated by the following diagram:

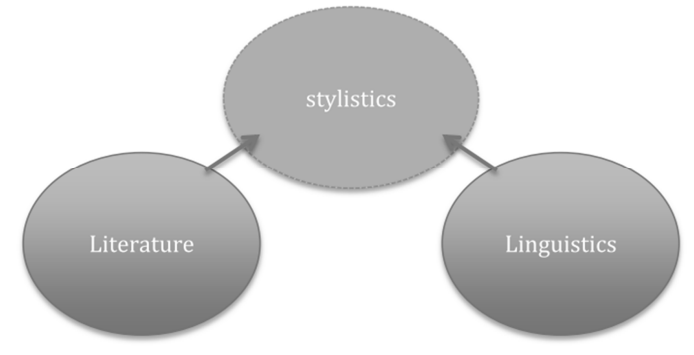

Stylistics embodies a third supplementary circle that feeds on the object of one (literary texts) and the rigour of the other (linguistic theories) to achieve different goals ${ }^{4}$.

\footnotetext{
4 The goals depend on whether the stylistician practises a "literary stylistics", in which case it is concerned with the interpretation of a text as
}

Stylistics is thus a discipline that is paradoxically marked by an inherent indisciplinarity.

As opposed to the "pure" linguist who seems to pledge allegiance to one school of thought and language and stick to it as hard as he or she can, defending its theoretical stronghold against competing schools, the stylistician draws from multiple linguistic wells depending on the nature of the text under study and what research question he or she is asking (it). As a context-dependent discipline, stylistics remains "adaptive". I will clarify the difference between the disciplinarity of linguistics and the indisciplinarity of stylistics by using Andrew Goatly's figure in his 2007 book where he deplores that linguists of a particular school have tended indeed to focus on one branch of the triangle at the expense of the other sides.

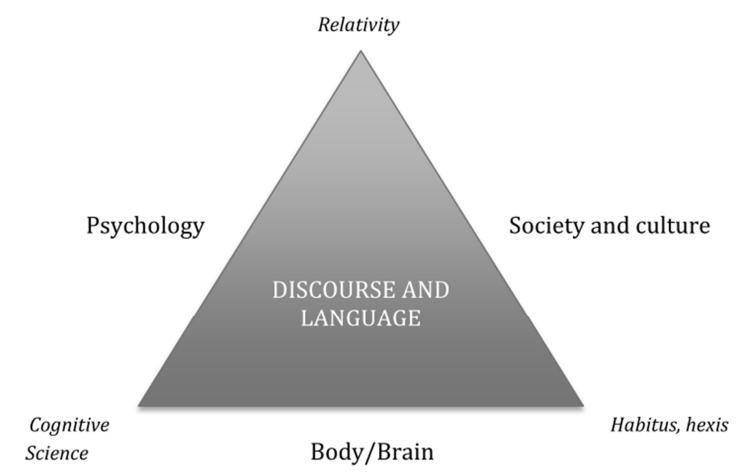

The base line is embodied by the linguistic school mostly under Chomskyan influence in its exclusive emphasis on the brain-located language capacity. The left-hand line is the prerogative of psycholinguists and pragmaticians working on "intended meaning and effects" like Grice, Sperber and Wilson, while the right-hand line focuses on discourse as part of generic types that are "determined by culture and ideology" mostly in the tradition of M.A.K. Halliday (Goatly, 2007 , p. 394). At the top of the triangle, the Whorfian notion of relativity accounts for "the influence of society and culture via language on thought". Habitus/hexis are Bourdieusian notions highlighting to what extent our bodies are "disciplined" by society. Cognitive science at the bottom-left corner is situated at the intersection

with the literary critic but from the specific angle of language, or whether it aims at confirming or questioning linguistic theory or challenging grammatical labels, which makes him or her more of a "linguistic stylistician" (in practice the boundaries are not as clear-cut). 
between psychological decisions and physical (re)action (Goatly, 2007, p. 395).

As opposed to disciplinary linguistics where the three different schools have evolved separately, not only is stylistics marked by an openness to the three lines of the triangle but it perceives them as three essential dimensions of language that need to be thought about together. Of course stylistics has developed its own branches but they do not erect exclusive boundaries around them. The different directions taken by stylistics will thus not be placed on the well-defined lines of the triangle but at their angles, thus bringing to light their permanent inbetweenness ${ }^{5}$ :

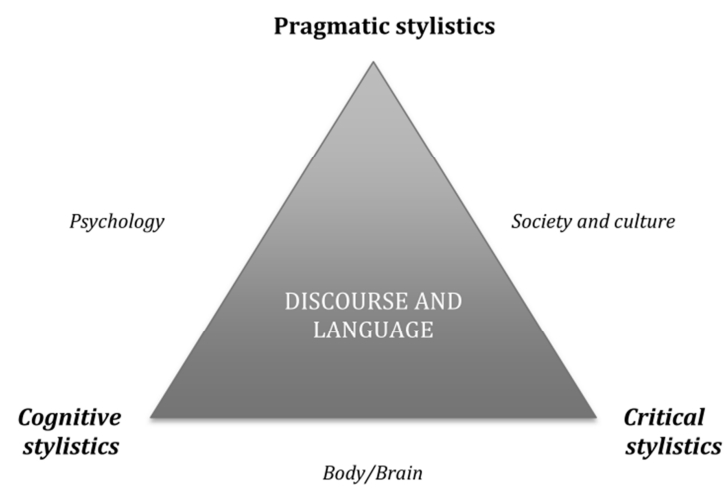

The essential solidarity between the different lines of the triangle can be illustrated if we take the example of cognitive stylistics: if it embodies a bridge between psychology and cognition, it is also united with the third side of the triangle. As Peter Stockwell puts it, "it is not enough to emphasise the embodied nature of cognition and language, without also recognising the various discursive practices that structure both society and language inextricably. Cognitive poetics must address this too" (Stockwell, 2002, p. 170). Likewise, if critical stylistics (named thus after Lesley Jeffries's 2010 book, Critical Stylistics. The Power of English) aims at uprooting the ideological assumptions

${ }^{5}$ Corpus stylistics, one recent development of stylistics, is not represented in this diagram because I see it as a methodological cross-cutting tool rather than a theoretical tool pertaining to one particular branch of stylistics. What makes stylistics specific as opposed to disciplinary linguistics is its refusal to define its tools a priori. The resort to particular linguistic tools and theories depends on the nature of the text under study and the questions that the researcher wants her research to answer. born by certain linguistic choices, it is not radically opposed to body considerations ${ }^{6}$. As Goatly exemplifies in his study of metaphors, language is also the means through which society disciplines our bodies (and vice versa). Pragmatic factors are also decisive in any discourse analysis (see below), hence the tendency in stylistics to think all the lines of the triangle as united and complementary.

\section{The specificity of stylistics}

What is the specificity of stylistics among language-based disciplines, like Critical Discourse Analysis, rhetorical studies or English for Specific Purposes, to name just a few of them that seem to share much with stylistics in their "applied" dimension? Drawing on Biber and Conrad's distinctions and definitions, a discourse/text can be analysed from three different perspectives: that of its genre, its register or its style. Generic markers in discourse conform to "the culturally expected way of constructing texts" (Biber and Conrad, 2009, p. 16). Register is more "functional" as it is directly influenced by the communicative situation: its linguistic features are those "required by the situational characteristics of the register" (Biber and Conrad, 2009, p. 18). Lastly every text (be it oral or written) has got style. They indeed define style as aesthetic choices made by an individual author ${ }^{7}$. In any analysis of discourse, the three dimensions need to be considered as inextricably linked, as illustrated in the interlaced rings here:

6 "Society uses metaphor themes to discipline our bodies, for example by imposing clock and industrial time on the factory or office worker or economic virtues which, by equating well-being or quality of life with wealth, discipline us to be frugal and hard-working" (Goatly, 2007, p. 395). Body (emotional) responses to a book and the psychological history of the reader are both key joint elements to be considered in a stylistics of emotions for instance (see Burke, 2011 for instance).

7 "In contrast, the linguistic patterns associated with styles are not functional. Rather, these are features associated with aesthetic preferences, influenced by the attitudes of the speaker/writer about language. That is, a speaker or author often has attitudes about what constitutes 'good style' resulting in the manipulation of language for aesthetic purposes" (Biber and Conrad, 2009, p. 18). 


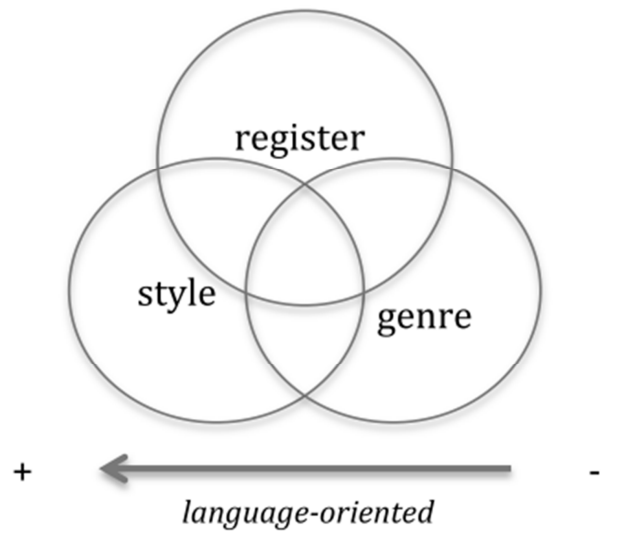

My contention is that the language-based disciplines mentioned above each tend to lay more emphasis on one of the three elements - without brushing aside the other two. If stylistics for instance foregrounds style, it does not completely discard the other two dimensions of the triad, unlike what Biber and Douglas's definition of style could make us suppose. Stylistic choices are always codependent with other contextual factors. Those factors are the backdrop against which style is performed. As opposed to stylistics, the American New Rhetoric lays more emphasis on the generic aspect of texts as it tends to emphasize the sociocultural context that surrounds particular genres more than its linguistic constituents ${ }^{8}$ (hence the left-pointing arrow of the figure above as regards the attention paid to language itself). Specialists of English for Specific Purposes tend to give centre stage to the register perspective, their study of linguistic features being subordinated to the communicative and functional purposes of the Text: texts pertaining to the register of the law for instance require the analysis of the specific technical terminology and syntactic characteristics of legal texts. Critical discourse analysis is closer to stylistics but seems to be born by contextual preoccupations that sometimes take precedence over linguistic features.

It must be underlined that style is not absent from register-determined texts: a scientific research paper for instance may be marked by clearly expected generic markers and be written in a characteristic register, yet it can still be moulded in a particular creative style - which can even rework its normative

${ }^{8}$ In this perspective genre is based on typicalities that serve as interpretative filters for social action (Miller, 1994, p. 29). register and genre from within ${ }^{9}$. But it seems safe to say that the more specialized the field of study becomes (politics, law, economy, medicine, etc.), the more normative the textual structure is, the further away it goes from the interest of stylistics $^{10}$. The singularity of stylistics may thus lie in its strong interest in the creativity" of language and discourse of any nature (literary, political, journalistic, commercial, everyday conversation, etc.).

We have first looked into what stylistics owes, then what it partially shares; we are now going to study what it gives and has given.

\section{The impact of stylistics}

If structuralist stylistics tended to perceive style as an object, contemporary stylistics perceives it "as the way we inhabit language" (Lecercle, 1993). In its adoption of an open integrational' $^{12}$ approach of language, stylistics has been able to exert a mediating function between linguistic knowledge and its application in the real world (see Toolan, 2009 , p. 14). Born by a paradigm of effectiveness rather than truth, it indeed combines (linguistic) knowledge with (communicative) know-how, which makes it particularly precious for the teaching of English as a first, second, foreign or other language. Where Chomsky for instance establishes a clear frontier between linguistics on the one hand and the teaching of language on the other (see Hudson, 2004), linguistics having for him no utility in everyday life $^{13}$, stylistics has been widely

${ }^{9}$ Style may then be construed as what can make register and genre evolve and change.

10 This does not imply that stylistics only studies linguistic deviations from the norm. What stylistics is interested in is the way texts make use of all the potentialities of language. In legal texts for instance creativity is not an expected feature (even though they often bear on metaphors).

1 See Simpson's introduction to the 2014 edition of his handbook of stylistics: "To do stylistics is to explore language, and, more specifically, to explore creativity in language use. Doing stylistics thereby enriches our ways of thinking about language" (Simpson, 2014, p. 3).

12 I'm using here Toolan's definition of integrationist (versus segrationist) linguistics: "Integrational thinking declines to accept that text and context are distinct and stable categories, prior to consideration of particular cases" (Toolan, 1996, p. 4).

${ }^{13}$ Chomsky's case is very interesting as he displays a complete schizophrenia between his 
resorted to in language teaching because of its contextualization of language in concrete situations of communication ${ }^{14}$.

Besides, teaching stylistics encourages students to "navigate" within language, to explore all its nooks and crannies in a variety of discourses, rather than have a static relationship with it. In this sense stylistics has an ethical role to play in education. As opposed to ancient rhetoric that would teach what was called an ethical style (lexis ethiké) ${ }^{15}$ where the orator had to express himself in accordance to his age, ethnic origin, social status and dispositions in order not to inspire mistrust, stylistic writing and speaking today teaches students to adopt different personas, those educational impostures enabling students to put into practice their discursive agency (beyond any social and cultural determination). By contrast with the teaching of rhetorical discipline, stylistics can serve as a liberating tool as it teaches "indiscipline" and role-playing. As James Paul Gee puts it, "What is important is not just how you say it, not just language in any sense, but who you

two fields of interest: we know his interest in politics. He has often denounced the sterile frontiers that the discipline of political science erects around its discipline, blocking the way to free knowledge according to Chomsky (who is not considered as a real political scientist, since he has not been trained in this discipline): "Arguing that impermeable disciplinary boundaries and the very division of the university into departments may be contributing to the screening out of certain questions and certain problems, he has proposed various forms of what might be called transdisciplinarity" (Baillargeon, 2010, p. 289). Yet within his own professional discipline, he displays the same compartmentalization he denounces in political science. Indeed, in schizophrenic contradiction, he makes linguistics a discipline unconcerned with ethical and political problems, and yet he rises up against the linguistic manipulations of the media and political rhetoric.

14 "There has been, often in response to demands to make courses accessible and 'relevant' to highfee paying international students, a growth in ESOL, significant developments in classroom research in second and foreign language studies, and a not unsurprising growth in pedagogic stylistics" (Carter, in Watson and Zyngier, p. vii).

15 «Si donc il emploie les mots appropriés à sa manière d'être, il manifestera le caractère : car un rustre et un homme éduqué ne sauraient user des mêmes mots, ni les dire de la même manière » (Aristote, Rhétorique, 1408 a [30-32]). are and what you're doing when you say it" /.../ We are each of us not a single who, but different whos in different contexts" (Gee, 2008 , p. 151). Teaching language in a stylistic perspective is thus to induce students to use different registers, genres and styles (see Sorlin, 2014) and to see how discourse can be creatively put to different effects and goals in different circumstances, and in so doing to learn to "get recognized as a given kind of person at a specific time and place" (Gee, 2008, p. 155).

This last sentence finds some resonance in recent studies in sociolinguistics that seem to owe much to the recent developments in literary stylistics: in their attempts to account for the complexity and heterogeneity of individuals' speeches, some sociolinguists have indeed been interested in the notion of "style" and stylization as a process (Auer, 2007; Coupland, 2001; 2007'6; Eckert and Rickford, 2001). The concept of style has enabled sociolinguists to address the shortcomings of the study of variation based on pre-established variables and more thoroughly study the way the self positions itself (and the other) in social space through particular linguistic choices (Auer, 2007, p. 13). Coupland's definition of stylistic analysis echoes the defining feature we have emphasized above: "stylistic analysis is the analysis of how style resources are put to work creatively" (Coupland, 2001, p. 3). The useful categories of register and dialect are not sufficient to account for the fact that an

16 To define stylistic sociolinguistics, Nikolas Coupland's starting point is Jean-Jacques Weber's following quotation in The Stylistic Reader:

\begin{abstract}
Meaning and stylistic effect are not fixed and stable, and cannot be dug out of the text in an archaeological approach, but they have to be seen as a potential which is actualized in a (real) reader's mind, the product of a dialogic interaction between author, the author's context of production, the text, the reader and the reader's context of reception-where context includes all sorts of sociohistorical, cultural and intertextual factors. (Weber, 1996, p.3)
\end{abstract}

Coupland replaces "reader" with the broader notion of "participants" which include speakers, listeners and analysts, but he shares Weber's aspirations for his own sociolinguistc stylistics (Coupland, 2007, p. 177). 
individual can create social meaning against a backdrop of social and linguistic constraints: as Judith $\mathrm{T}$. Irvine puts it, if studies of registers have been keen on highlighting varieties "as objects-inthemselves" bringing forward "relatively stable, institutionalised patterns and varieties", style "includes the more subtle ways individuals navigate among available varieties and try to perform a coherent representation of a distinctive self" (Irvine, 2001, p. 31).

Thus stylistic performance as studied in sociolinguistics or practised in stylistic (and creative writing) courses owes much to the stylistician's modern concept of style "as the way we inhabit our language".

\section{By way of conclusion}

We argued that stylisticians practise indisciplinarity, not for lack of disciplinary space, but as a refusal to comply with disciplinary frontiers. Stylistics is thus not afraid of bringing together tools and theories drawn from various disciplines in order to give the richest interpretation possible of a Text, for "the more complete and context-sensitive the description of language, then the fuller the stylistic analysis that accrues" (Simpson, 2014, p. 3). The porosity of the frontiers of stylistics explains its ability to give and take. The notion of style that is contained in its name (stylistics) itself invites multi-modal indisciplinarity as it also extends to other semiotic domains (like images, clothes, gestures or behaviours and so on). As it continues to draw bridges between various fields of knowledge and work on varied objects of study ${ }^{17}$, stylistics will never adopt disciplinary blinders/blinkers. Given its conception of language as fundamentally contextualized, it can only exist as a crossdisciplinary field. Stylistics is indeed inevitably led to venture into other disciplines belonging to social science (history, politics, sociology, psychology, etc.) if the linguistic study is to have any fruitful resonance in a practical context. If it were asked to establish prophetic truths about language to be followed by faithful disciples, it would lose nothing less than its very essence.

17 "And there is a growing recognition that the field of stylistics is better placed than many to explore the challenge of new media and to explore the literary in terms of the multimodal creation of virtual worlds, drawing on students' own palpable experience of new representational and poetic clines across fiction and reality, speech and writing, texture and visuality" (in Watson and Zyngier, p. $\mathrm{x}$ ).

\section{References}

ARISTOTE, 2007. Rhétorique. Présentation et traduction par Pierre Chiron. Paris: Flammarion.

AUER, P. ed., 2007. Style and social identities. Alternative approaches to linguistic heterogeneity. Berlin, New York: Mouton de Gruyter.

BAILLARGEON, N., 2010. The practice of intellectual self-defense in the university. In J. Bricmont and J. Franck, eds. Chomsky Notebook. New York: Columbia University Press, pp. 283-292.

BIBER, D. and CONRAD, S., 2009. Register, genre and style. Cambridge: Cambridge University Press.

BURKE, M., 2011 . Literary reading, cognition and emotion. London: Routledge.

COUPLAND, N., 2001. Language, situation and the relational self: Theorising dialect style in sociolinguistics. In P. Eckert and J. R. Rickford, eds. Style and sociolinguistic variation. Cambridge and New York: Cambridge University Press, pp. 185-210.

COUPLAND, N., 2007. Style. language variation and identity. Cambridge: Cambridge University Press.

ECKERT, P. and RICKFORD, J. eds., 2001. Style and sociolinguistic variation. Cambridge:

Cambridge University Press.

FOUCAULT, M., 1979. L'Ordre du discours. Paris: Gallimard.

GEE, J. P., 2008. Social linguistics and literacies. London, New York: Routledge, $3^{\text {rd }}$ ed.

GOATLY, A., 2007. Washing the brain. Metaphor and hidden ideology. Amsterdam, Philadelphia: John Benjamins Publishing.

HUDSON, R., 2004. Why education needs linguistics (and vice versa). Journal of Linguistics, vol. 40 , no. 1 , pp. 105-130. 
IRVINE, J. T., 2001. Style as distinctiveness: the culture and ideology of linguistic differentiation. In: P. Eckert and J. R. Rockford, eds. Style and sociolinguistic variation. Cambridge: Cambridge UP.

JEFFRIES, L., 2010. Critical stylistics. The power of English. Basingstoke: Palgrave/Macmillan. LECERCLE, J-J., 1993. The current state of stylistics. The European English Messenger, vol. 2, no. 1, pp. 14-18.

LOTY, L., 2005. Pour l'indisciplinarité. In: J. V. Douthwaite and M. Vidal Mary, eds. The interdisciplinary century: Tensions and convergences in eighteen-century art, history and literature. Oxford: Voltaire Foundation, pp. 245-259.

MILLER, C. R., 1994. Genre as social action. In: A. Freedman and P. Medway, eds. Genre and the new rhetoric. London: Taylor \& Francis, pp. 23-42.

SIMPSON, P., 2014. Stylistics. London: Routledge, 2 nd ed.

SORLIN, S., 2014. La Stylistique anglaise. Théories \& Pratiques. Rennes: Presses Universitaires de Rennes.

STOCKWELL, P., 2002. Cognitive poetics. An introduction. London, New York: Routledge.

TOOLAN, M., 1996. Total speech. An integrational linguistic approach to language. Durham \& London: Duke University Press.

TOOLAN, M., 2009. Language teaching. Integrational linguistic approaches. London, New York: Routledge.

WATSON, G. and Zyngier S., 2007. Literature and stylistics for language learners. Theory and practice. Foreword by Ronald Carter. London: Palgrave Macmillan.

WEBER, J-J., 1996. The stylistics reader: From Roman Jakobson to the present. London: Arnold.

\section{Author's address and contact details}

Sandrine Sorlin

Aix-Marseille University / LERMA / IUF

Les Terrasses St Jérôme. Bât. 5. 8 Avenue de la Cible.

13100 Aix-en-Provence

France

Phone: +33683136167

E-mail: sandrine.sorlin@univ-amu.fr 